\title{
Frameless
}

Volume 1 | Issue 1

Article 25

November 2019

\section{Social Augmented Reality}

Renée Stevens
Syracuse University, rcsteven@syr.edu

Follow this and additional works at: https://scholarworks.rit.edu/frameless

\section{Recommended Citation}

Stevens, Renée (2019) "Social Augmented Reality," Frameless: Vol. 1: Iss. 1, Article 25.

DOI: 10.14448/Frameless.01.012

Available at: https://scholarworks.rit.edu/frameless/vol1/iss1/25

This Article is brought to you for free and open access by RIT Scholar Works. It has been accepted for inclusion in Frameless by an authorized editor of RIT Scholar Works. For more information, please contact ritscholarworks@rit.edu. 


\title{
FRAMELESS
}

\section{Social Augmented Reality}

\author{
Renée Stevens \\ Assistant Professor and Associate Chair \\ Syracuse University
}

\begin{abstract}
My creative research looks at how Augmented Reality (AR) can help overcome Learning Disabilities. This focus has directed me to develop a number of ideas and concepts that seek to understand how the addition of information in an augmented view could help tackle some of the challenges different Learning Disabilities present while, at the same time, appealing to a larger audience. This concept was the foundation for creating the immersive mobile application tagAR ${ }^{\mathrm{TM}}$, which adds a digital name tag into your augmented view, replacing the traditional "Hello, my name is" sticker version. It allows you to see the names of people around you hovering above their heads at all times. Currently, the app is reliant on the user holding up a mobile device to use the camera so that the application can add the name tags to the view on your screen. As mainstream technology continues to advance, this app will work for wearable devices, eliminating the need to hold up your phone, which is a bit socially awkward. The target audience of the app is those who have trouble remembering people's names, those who will benefit from having a visual of the names of people around them and for those who want to network and meet new people at social and educational events such as conferences or workshops. Through the design and development of this app, I have been exploring how the social aspect can be extended beyond just the name display and user search features to include a customizable tags that can be searchable, so users can connect, find people with similar interests, share contact information as well as connect with others on multiple social media platforms. I will discuss the research, design and developmental processes that influenced the concept and functionality of this social app using AR.
\end{abstract}

Keywords: augmented reality, learning disabilities, dyslexia, name tags, tagAR, UI/UX design, mobile application 
Vol. 1, No. 1 - 2019

Frameless

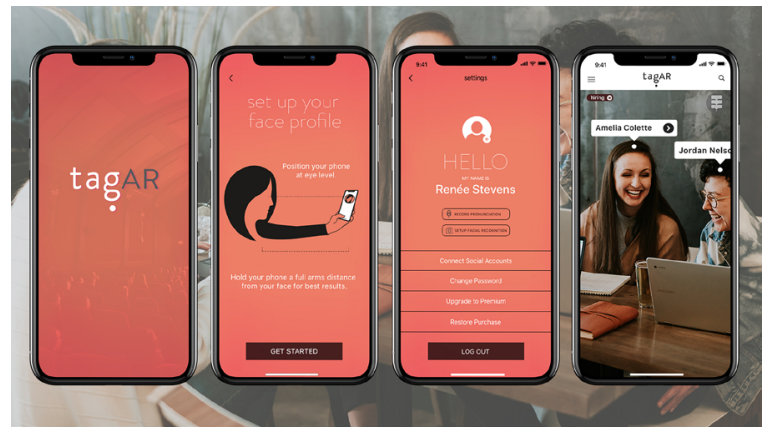

Fig. 1. Screenshots of tagAR mobile application, full app experience available for download in the Apple Store. Summer 2019:

https://apps.apple.com/us/app/tagar/ id1291822880

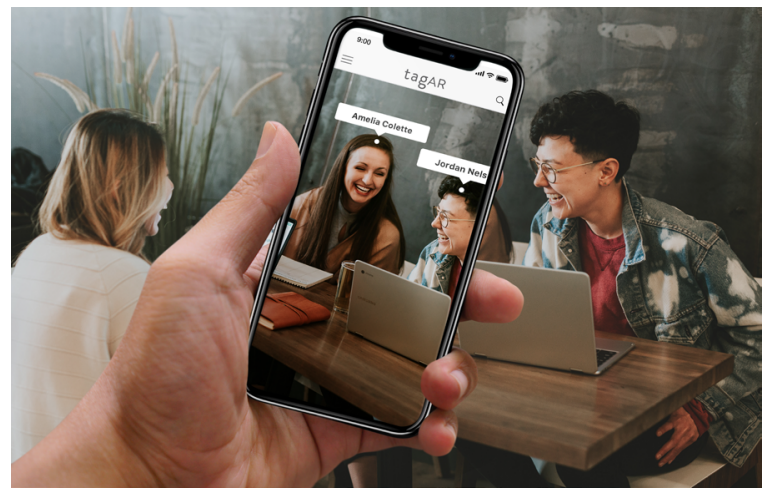

Fig. 2. Prototype of tagAR showing Augmented nametags using your mobile device. Fall 2018. Photo credit: Brooke Cagle.

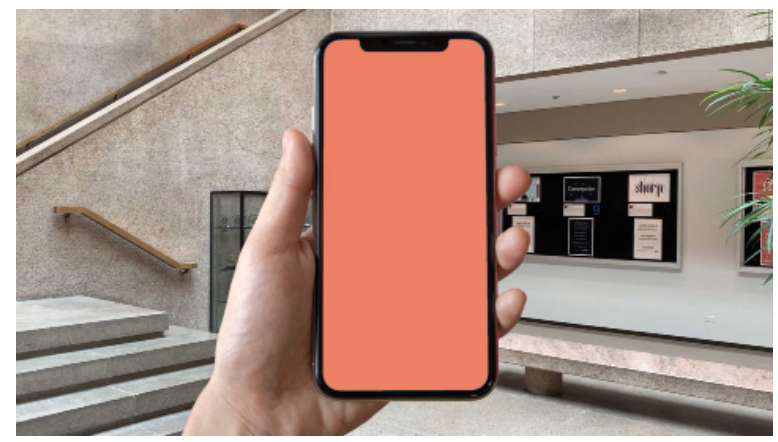

Spring 2019. Video credit: Renée Stevens



Fig. 3. Prototype image of the tagAR experience using wearable Augmented Reality glasses to access the nametags directly in your view without the need to hold up your mobile phone. Spring 2018.

A prototype of this mobile application, tagAR can be viewed online:

https://vimeo.com/229070725 